\title{
New product development with the innovative biomolecular sublingual immunotherapy formulations for the management of allergic rhinitis
}

This article was published in the following Dove Press journal:

Biologics:Targets and Therapy

12 September 2014

Number of times this article has been viewed

\author{
Franco Frati' \\ Lorenzo Cecchi ${ }^{2,3}$ \\ Enrico Scala ${ }^{4}$ \\ Erminia Ridolo 5 \\ Ilaria Dell'Albani' \\ Eleni Makrí \\ Giovanni Pajno ${ }^{7}$ \\ Cristoforo Incorvaia ${ }^{6}$ \\ 'Medical and Scientific Department, \\ Stallergenes, Milan, Italy; \\ ${ }^{2}$ Interdepartmental Centre of \\ Bioclimatology, University of Florence, \\ Florence, Italy; ${ }^{3}$ Allergy and Clinical \\ Immunology Section, Azienda Sanitaria \\ di Prato, Prato, Italy; ${ }^{4}$ Experimental \\ Allergy Unit, IDI-IRCCS, Rome, \\ Italy; ${ }^{5}$ Department of Clinical and \\ Experimental Medicine, University \\ of Parma, Parma, Italy; ${ }^{6}$ Allergy/ \\ Pulmonary Rehabilitation, ICP \\ Hospital, Milan, Italy; ${ }^{7}$ Department of \\ Pediatrics, Allergy Unit, University of \\ Messina, Messina, Italy
}

Correspondence: Franco Frati Medical and Scientific Department, Stallergenes, Via Tibullo 2, 20I5I, Milan, Italy

Tel +39023 3454327

Fax +390270058778

Email ffrati@stallergenes.it

\begin{abstract}
The molecular allergy technique, currently defined as component-resolved diagnosis, significantly improved the diagnosis of allergy, allowing for differentiation between molecules actually responsible for clinical symptoms (genuine sensitizers) and those simply cross-reacting or shared by several sources (panallergens), thus influencing the appropriate management of a patient's allergy. This also concerns allergen immunotherapy (AIT), which may be prescribed more precisely based on the component-resolved diagnosis results. However, the advance in diagnosis needs to be mirrored in AIT. According to consensus documents and to expectations of specialists, therapy should be based on standardized extracts containing measured amounts of the clinically relevant molecules, ie, the major allergens. The new generation of extracts for sublingual immunotherapy fulfills these requirements and are thus defined as biomolecular (BM). BM refers to natural extracts with a defined content of major allergens in micrograms. All Staloral $\mathrm{BM}$ products are indicated for the treatment of allergic rhinitis with or without asthma. The effectiveness of AIT is related to its ability to modify the immunological response of allergic subjects. The 5-grass and house dust mite extracts were evaluated addressing the T helper 1, T helper 2, and T helper 3 cells by polymerase chain reaction array on mRNA extracted from Waldeyer's ring tissue (adenoids). Sublingual immunotherapy with a defined content of major allergens in micrograms induced a strong downregulation of genes involved in T helper 2 and T helper 1 activation and function, allowing the definition of the immunologic effect as "bio-homeostatic". This clinical and immunological model must be implemented with respect to other allergens, thus expanding the application of a treatment with a unique disease-modifying capacity.
\end{abstract}

Keywords: allergen immunotherapy, allergy, component resolved diagnosis, major allergens, allergen molecules

\section{Introduction}

The birth of molecular allergology was a major advance in the diagnosis of hypersensitivity diseases. In fact, the technique of component resolved diagnosis, measuring the specific IgE antibodies to individual allergen molecules (natural or recombinant), rather than to the entire sources containing them, provides more precise data for the diagnosis. ${ }^{1}$ In particular, separating the molecules actually responsible for clinical symptoms (genuine sensitizers) from those simply cross-reacting or shared by several sources (panallergens) allows for the identification of causative allergens in polysensitized patients and, hence, appropriate management of the patient's allergy. ${ }^{2}$ This is true for food allergy ${ }^{3}$ and is of paramount importance with respect to respiratory allergy. Actually, more refined and precise pollen maps were recently obtained by using molecular techniques in place of the common measurement of pollen grains. ${ }^{4}$ 
As far as the prescription of allergen immunotherapy (AIT) is concerned, Sastre et al demonstrated that the use of molecular diagnosis substantially changed the previous decision, which was based on conventional diagnosis. ${ }^{5}$ This observation was confirmed also in children with pollen allergy. ${ }^{6}$ However, the concern is the choice of the allergen source to be used (birch pollen, grass pollen, olive pollen, etc) but not the molecular composition of the extract. In fact, the possibility of performing a tailored AIT, that is, based on products containing a composition of recombinant allergens reproducing the patient's individual sensitization profile, has long been envisioned. ${ }^{7}$ However, considering the large number of different sensitization profiles, the commercial availability of these products is unlikely, due to the high cost required to register each product. Notably, a controlled trial on patients with rhinoconjunctivitis induced by birch pollen showed that the clinical efficacy of two preparations containing the recombinant or natural major allergen Bet $v 1$ from birch pollen was similar to that of a high-quality, licensed birch pollen extract. ${ }^{8}$ Indeed, this shows a noninferiority of the molecular preparations versus high-quality conventional extracts, and makes apparent that when the diagnosis is sound and the AIT product fulfills the quality standards, the results are clinically comparable to molecular preparations.

The importance of titrating the major allergen content in micrograms $(\mu \mathrm{g})$ was recently supported by the opinions of allergy specialists. In a recent survey, specialists evaluated the importance of the different issues with respect to AIT, ranking high the documentation of the content of the major allergens in $\mu \mathrm{g}$, along with the level of evidence-based validation of efficacy and safety, and the standardization of the products. ${ }^{9}$ Actually, consensus documents on AIT view the documentation on the content of major allergens in $\mu \mathrm{g}$ as a need to be met by producers. ${ }^{10,11}$ This is also a requirement by the European Medicine Agency guidelines for the production and quality of AIT preparations. ${ }^{12}$

Here, we review the background and the characteristics of Staloral biomolecular (BM) products for AIT, based on defined contents in $\mu \mathrm{g}$ of major allergens.

\section{Production technology}

Each allergen source contains a large number of components, some of them eliciting a specific IgE response. The frequency of IgE binding in a population of patients allergic to a given source, higher or lower than $50 \%$, defines major allergens and minor allergens, respectively. ${ }^{13}$ For decades, allergen extracts for AIT were measured by their protein content, the protein nitrogen unit being the most used quantification unit; but, in the 1980s, the development of international standards redefined biological potency units..$^{14}$ Among these units, the histamine equivalent in prick testing, the biological units, and the bioequivalent allergen units were the most used. Table 1 shows the characteristics of such units. ${ }^{15}$ In 2008, the CREATE (Certified REference Materials for Allergenic Products and Validation of MeThods for their Quantification) project, involving research laboratories, allergen manufacturers, clinical researchers, and biotech companies from European Union member states, was launched with the aim to develop certified reference materials for allergen extracts and to validate the enzyme-linked immunosorbent assays (ELISA) for the measurement of major allergens. ${ }^{16}$

The measurement in $\mu \mathrm{g}$ of the content in major allergens of allergenic products is currently considered mandatory in the certification of their quality. ${ }^{11,15}$ Every manufacturer of allergen extracts has its in-house reference standard measuring the allergenic potency. For extracts from Stallergenes (Antony, France), the potency is measured by the index of reactivity (IR) per milliliter, with $100 \mathrm{IR} / \mathrm{mL}$ corresponding to the allergenic potency of an extract eliciting a mean wheal diameter of $7 \mathrm{~mm}$ by skin prick tests performed in patients allergic to the specific allergen source. ${ }^{17}$ The product Staloral300, obtained from the same source material used for BM products but titrated only in IR, was demonstrated to be efficacious by 20 double-blind, placebo-controlled trials on patients allergic to pollens and dust mites. ${ }^{18}$ The quantification of allergens is generally made by antibody-based techniques such as radioimmunoassay, ELISA, radial immunodiffusion, and rocket immunoelectrophoresis (RIE), but due to the variations of measurement depending on the technique used, the modern approach used in production to quantify the relevant allergens is also based on mass spectrometry (MS). ${ }^{19} \mathrm{MS}$ is an analytical technique

Table I Biological potency units for allergen extracts

\begin{tabular}{|c|c|}
\hline $\begin{array}{l}\text { Type of biological } \\
\text { potency units }\end{array}$ & Characteristics \\
\hline HEP & $\begin{array}{l}\text { I0 HEP corresponds to the allergen } \\
\text { concentration that elicits the same wheal } \\
\text { size in skin prick testing as the histamine } \\
\text { dihydrochloride control at } 10 \mathrm{mg} / \mathrm{mL} \text {. }\end{array}$ \\
\hline BU & $10,000 \mathrm{BU} / \mathrm{mL}$ is equivalent to $10 \mathrm{HEP}$. \\
\hline BAU & $\begin{array}{l}\text { Based on the intradermal dilution for } 50 \mathrm{~mm} \\
\text { sum }\left(D_{50}\right) \text { of erythema diameters from skin } \\
\text { test. } A D_{50} \text { of } 14 \text { is arbitrarily assigned } \\
100,000 \mathrm{BAU} / \mathrm{mL} \text {. The allergenic potency of } \\
\text { an unknown extract can be calculated by the } \\
\left.\text { formula } B A U / \mathrm{mL}=100,000 \times 3^{(D 50-14}\right) \text {. }\end{array}$ \\
\hline
\end{tabular}

Abbreviations: $B A U$, bioequivalent allergen unit; $B U$, biological unit; $\mathrm{HEP}$, histamine equivalent in prick testing. 
that produces spectra of the masses of the atoms or molecules comprising a sample of material, which was applied since 2002 in the study of allergens. ${ }^{20}$ The use of these techniques, ie, the quantification in $\mu \mathrm{g}$ with the respective measurement in $100 \mathrm{IR}$, led to the documentation of the correspondence between IR and $\mu \mathrm{g}$ for the different allergens (Table 2). The use of MS has overcome the limitation of antibody-based immunoassays, which, because of the variability of the natural allergen structure, often resulted in excess of specificity and, consequently, in an underestimated allergen concentration. Instead, MS is able to detect the peptides that are conserved in all the different isoforms, allowing the proper quantification of allergens naturally occurring in different isoforms, such as the group 1 allergens from grass pollen or Der $\mathrm{p} 2$ from Dermatophagoides pteronyssinus. ${ }^{21}$ Another prerequisite for quality is the stability of the product, which is essential in maintaining allergenic potency. High temperature is the most critical factor affecting stability. The Staloral extracts for AIT from Stallergenes were tested for temperature during transport in the warm season, as occurs when the product is sent from the manufacturer to a patient's house, using a thermal-insulating packaging. ELISA-inhibition tests of extracts subjected to temperatures up to $45^{\circ} \mathrm{C}$ showed that an immunologic activity higher than $75 \%$ of that measured in the production phase was detectable, with no significant difference with extract maintained for the same time at the controlled temperature of $5^{\circ} \mathrm{C} .^{22}$

\section{Grass pollen}

In the long history of AIT, grass pollen is a protagonist. In fact, the first study introducing this treatment concerned grass-pollen allergy and the same model was the object of the

Table 2 Major allergens content in most-used allergen extracts for AIT

\begin{tabular}{lll}
\hline Allergen source & Major allergen & $\begin{array}{l}\text { Quantification } \\
\text { in micrograms } \\
\text { corresponding } \\
\text { to I 00 IR }\end{array}$ \\
\hline Grass pollen & Group 5 allergens & 7 \\
Birch pollen & Bet v I & 50 \\
Olive pollen & Ole e I & 10 \\
Cypress pollen & Jun a I & 100 \\
Ragweed pollen & Amb a I & 100 \\
Dermatophagoides & Der P I & 20 \\
pteronyssinus & Der P 2 & 4 \\
Dermatophagoides farinae & Der f I & 50 \\
Cat epithelium & Fel d I & 80 \\
Dog epithelium & Can f I & 20 \\
Alternaria & Alt a I & 6 \\
\hline
\end{tabular}

Abbreviations: AIT, allergen immunotherapy; IR, index of reactivity. first controlled trial published 40 years later. ${ }^{23}$ In the $1990 \mathrm{~s}$, sublingual immunotherapy (SLIT) was added to the classical form of subcutaneous immunotherapy (SCIT), mainly for safety reasons, and currently is generally accepted as a valid option. ${ }^{24}$ The large number of trials of AIT with grass-pollen extracts allowed the performance of a meta-analysis on the efficacy of this treatment, including 36 placebo-controlled trials with SCIT or SLIT on patients with grass-polleninduced allergic rhinitis. ${ }^{25}$ The authors found that SCIT was more effective than SLIT in reducing allergic symptoms and drug consumption, but it must be noted that the differences in administered doses were much more marked with SLIT than with SCIT. The dose-dependency of efficacy of AIT is indisputable. ${ }^{26}$ An analysis of SLIT trials revealed that efficacy was much higher in studies based on the administration of high doses rather than in those with low doses. ${ }^{27}$

In particular, the position paper on SLIT by the World Allergy Organization stated "a dose dependency of the efficacy of SLIT was observed, and the optimal monthly

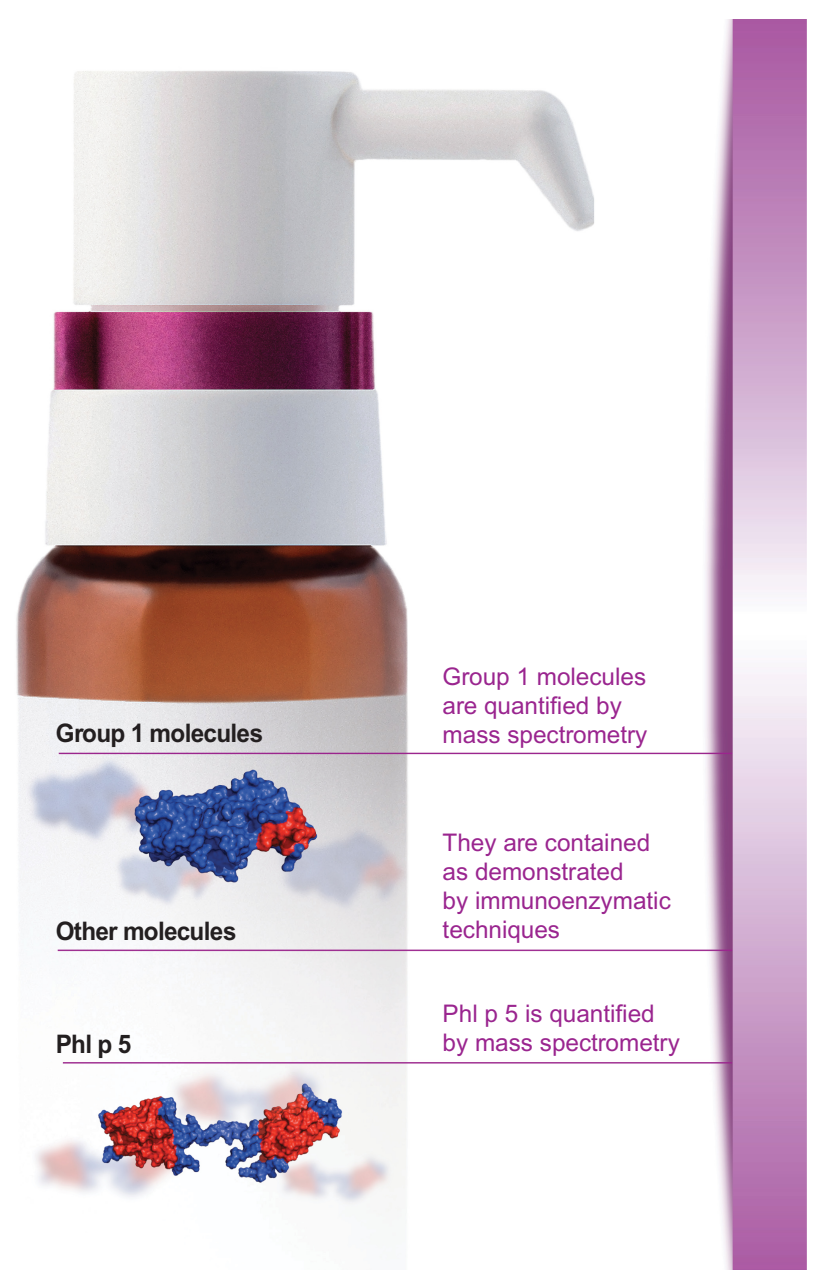

Figure I The molecular profile of Staloral biomolecular grasses. 
maintenance dose for grasses was identified as about $600 \mathrm{mcg}$ of the major allergen". ${ }^{10}$ This requirement is fulfilled by modern products for SLIT, such as Staloral BM grasses, ${ }^{28}$ but not by many pollen extracts commercially available. All the clinical relevant allergens are contained in the natural extract product, as assessed by immunoenzymatic techniques and MS, but only the major allergen Phl p 5 is measured in $\mu \mathrm{g}$. Recently, the group 1 grass molecules were also quantified in $\mu \mathrm{g}$ by using MS (Figure 1). ${ }^{29}$

Another important aspect of AIT is the schedule of administration: Staloral BM grasses are indicated for a precoseasonal schedule, based on a start of treatment before the pollination period of grasses, to be continued during the pollen season, and to be completed at the end of grass-pollen season. As for AIT with inhalant allergens in general, ${ }^{10,26}$ the treatment must be performed for 3 consecutive years to ensure the so-called carry-over effect; that is, the persistence over time of the clinical benefit following the discontinuation of treatment. ${ }^{30}$

The indications of recommended doses expressed in $\mu \mathrm{g}$ of major allergens, as done for grass pollen, for products containing other clinically important allergens will further support the confidence in SLIT efficacy and safety.

\section{Immunological effects}

The mechanisms of action of AIT include early desensitization effects that correspond to the efficacy on symptoms after a few weeks of treatment, as well as effects in later stages, such as: the modulation of T- and B-cell responses and related antibody isotypes from the T helper 2 (Th2) pattern typical of allergic subjects to a T helper 1 (Th1) pattern; and the generation of $\mathrm{T}$ regulatory cells that play a key role in regulating the immunologic processes, leading to peripheral tolerance to allergens and the inhibition of migration of eosinophils, basophils, and mast cells to tissues, as well as the release of their mediators. ${ }^{31}$

There is a substantial similarity in the immunologic effects of SCIT and SLIT, with a pivotal role in the latter for dendritic cells of the oral mucosa. ${ }^{31-33}$ A recent study highlighted the active participation in the immunologic response of the Waldeyer's ring (which is the arrangement

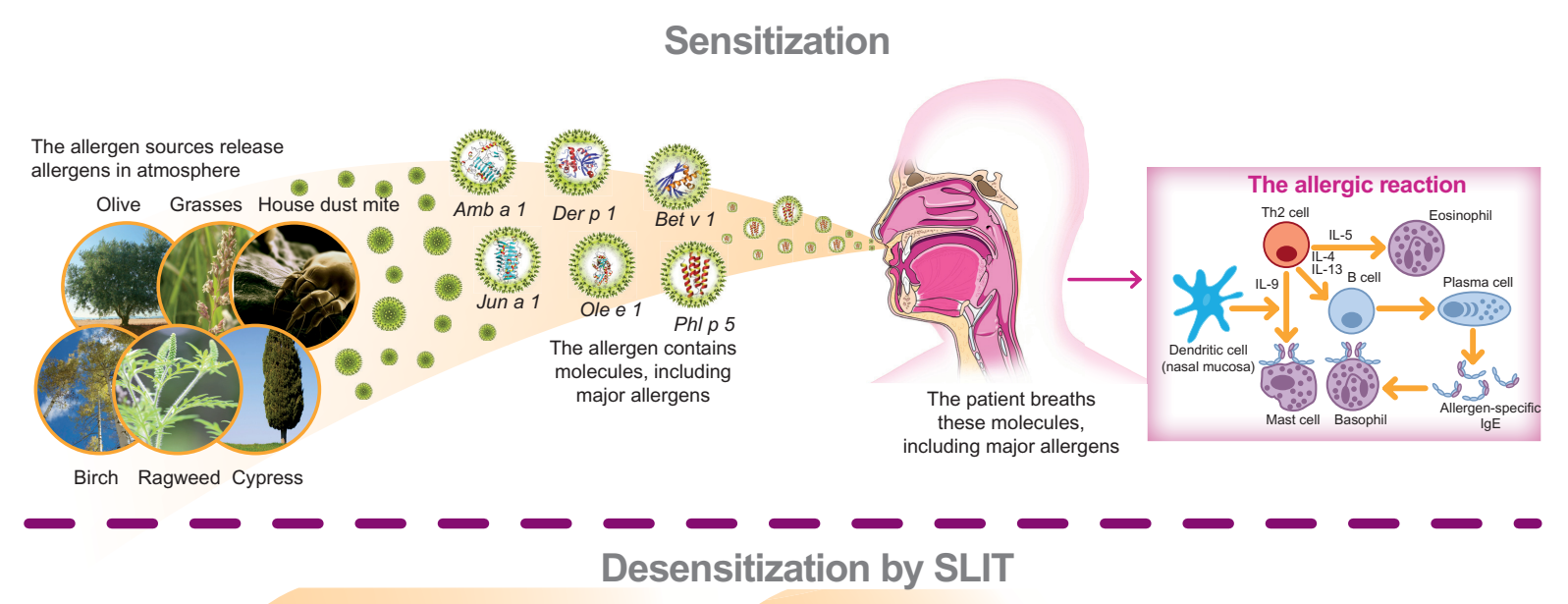

The Waldeyer's ring (adenoids, palatine tonsils, tubal tonsils,

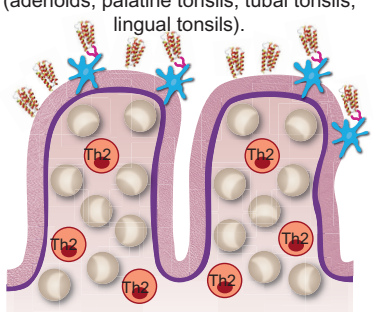

The major allergen contained in the SLIT product is captured by dendritic cell. SLIT with a defined content in micrograms of major allergen is able to down-regulate the expression of $I L-4$ gene in Th2 lymphocytes (specific anti-lgE like effect).

Desensitization by SLIT

The oral mucosa

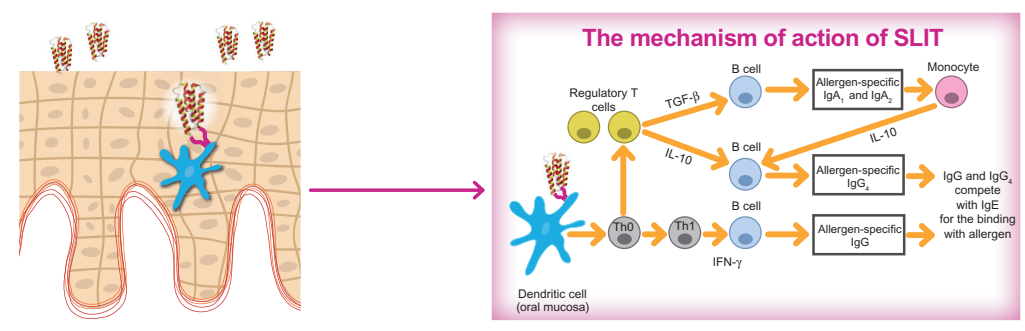

The major allergen contained in the SLIT product is captured by dendritic cell. For this reason it is necessary to determine if major allergen is present and in which amoun in the product.

Figure 2 From allergen sources to allergen molecules: the molecular journey.

Abbreviations: SLIT, sublingual immunotherapy; Th0, T helper 0; ThI, T helper I; Th2, T helper 2; Ig, immunoglobulin; IL, interleukin; IFN, interferon. 
of lymphoid tissue in the pharynx, including adenoids, tubal tonsils, palatine tonsils, and lingual tonsils ${ }^{34}$ to the allergens (grass pollen or dust mites) administered by SLIT extracts with a defined content in $\mu \mathrm{g}$ of major allergens. The evaluation addressed the Th1, Th2, and Th3 cells by performing a polymerase chain reaction array on mRNA extracted from adenoid samples in nonallergic children and in SLIT-treated allergic children. In the former, a typical Th1 pattern was found. SLIT induced a strong downregulation of genes involved in Th2 and Th1 activation and function. In particular, in SLIT-treated allergic children, IL-4, CCR2, CCR3, and PTGDR2 (Th2 related genes) and CD28, IL-2, and INHA (Th1 related genes) expression was decreased. This downregulation effect acting on immunologic homeostasis could be defined as "bio-homeostatic" and is considered to represent, based on the localization of Waldeyer's ring, an immunological response typical of SLIT, with a defined content in $\mu \mathrm{g}$ of major allergens (Figure 2), and not shared by other routes of administration of AIT. Such ex vivo demonstration of the dose dependence of the immunologic response to SLIT confirms previous in vitro studies showing that internalization of pollen allergens by dendritic cells was related to the administered dose..$^{35}$

\section{Future developments}

The improvement of the quality of products for AIT has the potential to increase the credibility of this treatment that, despite its long history, is often underestimated by the medical community. The quantification of major allergens is a powerful tool in achieving a grade of standardization that will enable AIT products to be comparable to drugs, ${ }^{36}$ thus accomplishing the objectives indicated by the European Academy of Allergy and Clinical Immunology that consist of improving the allergic patient's quality of life, reducing the long-term costs and burden of allergies, and changing the course of the disease. ${ }^{37}$ Until now, AIT did not receive adequate attention from European institutions, including research funding bodies. The general population remained unaware of the potential benefits of AIT, such as the long-lasting effects following its discontinuation. Undoubtedly, the confusion caused by the availability of a large array of products with very dissimilar quality has negatively influenced the opinion of physicians and patients on this treatment. The innovation provided by the introduction of high-quality, standardized products with a defined content of major allergens in $\mu \mathrm{g}$ has the potential to reverse the trend of a marginal clinical use of AIT. ${ }^{38}$ However, the process needs to be wisely managed and is strictly dependent upon the certain identification in each patient of the causative allergen by reliable diagnostic procedures, and upon the presence of the causal allergen molecule(s) and its quantification in AIT products.

\section{Conclusion}

The introduction of allergen extracts containing known quantities of major allergens is a major step toward a qualitative improvement of AIT that may match the diagnostic advance achieved by molecular-based diagnosis. ${ }^{39}$ In fact, supporting the improved diagnostic approach by an equal molecule-driven development of products designed for AIT, in terms of the identity of the allergen molecules detected as responsible for symptoms and their appropriate quantity, will enable stimulation of a virtuous course for patients with respiratory allergy, including those with a polysensitization apparently preventing AIT use. ${ }^{40}$ This may result in expanding the application of a treatment with a unique capacity to modify the natural history of allergy.

\section{Disclosure}

Franco Frati is an employee of Stallergenes Italy. Ilaria Dell'Albani was an employee of Stallergenes Italy at the time of the submission of the article. Cristoforo Incorvaia is a scientific consultant for Stallergenes Italy. The other authors declare no conflicts of interest in this work.

\section{References}

1. Valenta R, Lidholm J, Niederberger V, Hayek B, Kraft D, Grönlund H. The recombinant allergen-based concept of component resolved diagnostics and immunotherapy (CRD and CRIT). Clin Exp Allergy. 1999;29(7):896-904.

2. Rossi RE, Melioli G, Monasterolo G, et al. Sensitization profiles in polysensitized patients from a restricted geographical area: further lessons from multiplexed component resolved diagnosis. Eur Ann Allergy Clin Immunol. 2011;43(6):171-175.

3. Incorvaia $\mathrm{C}$, Rapetti A, Aliani M, et al. Food allergy as defined by component resolved diagnosis. Recent Pat Inflamm Allergy Drug Discov. 2014;8(1):59-73.

4. Cecchi L, Dell'Albani I, Frati F. Towards a global vision of molecular allergology: a map of exposure to airborne molecular allergens. Eur Ann All Clin Immunol. 2013;45(Suppl 2):17-23.

5. Sastre J, Landivar ME, Ruiz-García M, Andregnette-Rosigno MV, Mahillo I. How molecular diagnosis can change allergen-specific immunotherapy prescription in a complex pollen area. Allergy. 2012;67(5): 709-711.

6. Stringari G, Tripodi S, Caffarelli C, et al. The effect of componentresolved diagnosis on specific immunotherapy prescription in children with hay fever. J Allergy Clin Immunol. Epub April 30, 2014

7. Crameri R, Rhyner C. Novel vaccines and adjuvants for allergen-specific immunotherapy. Curr Opin Immunol. 2006;18(6):761-768.

8. Pauli G, Larsen TH, Rak S, et al. Efficacy of recombinant birch pollen vaccine for the treatment of birch-allergic rhinoconjunctivitis. J Allergy Clin Immunol. 2008;122(5):951-960.

9. Canonica GW, Passalacqua G, Incorvaia C, et al. Ranking in importance of allergen extract characteristics for sublingual immunotherapy by Italian specialists. Allergy Asthma Proc. 2014;35(1):43-46. 
10. Canonica GW, Bousquet J, Casale T, et al. Sub-lingual immunotherapy: World Allergy Organization Position Paper 2009. Allergy. 2009; 64 Suppl 91:1-59.

11. Zuberbier T, Bachert C, Bousquet PJ, et al. GA² LEN/EAACI pocket guide for allergen specific immunotherapy for allergic rhinitis and asthma. Allergy. 2010;65(12):1525-1530.

12. Committee for Medicinal Products for Human Use (CHMP). Guideline on Allergen Products: Production and Quality Issues. EMEA/CHMP/ BWP/304831/2007. London: European Medicines Agency; 2008.

13. Johansson SG, Bieber T, Dahl R, et al. Revised nomenclature for allergy for global use; report of the Nomenclature Review Committee of the World Allergy Organization. J Allergy Clin Immunol. 2004;113(5): 832-836.

14. Turkeltaub PC. Biological standardization of allergen extracts. Allergol Immunopathol (Madr). 1989;17(2):53-65.

15. Becker WM, Vogel L, Vieths S. Standardization of allergen extracts for immunotherapy: where do we stand? Curr Opin Allergy Clin Immunol. 2006;6(6):470-475.

16. van Ree R, Chapman MD, Ferreira F, et al. The CREATE project: development of certified reference materials for allergenic products and validation of methods for their quantification. Allergy. 2008;63(3): 310-326.

17. Hrabina M, Dumur JP, Sicard H, Viatte A, André C. Diagnosis of cypress pollen allergy: in vivo and in vitro standardization of a Juniperus ashei pollen extract. Allergy. 2003;58(8):808-813.

18. Frati F, Scurati S, Puccinelli P, et al. Development of an allergen extract for sublingual immunotherapy - evaluation of Staloral. Expert Opin Biol Ther. 2009;9(9):1207-1215.

19. Batard T, Nony E, Hrabina M, Chabre H, Frati F, Moingeon P. Advances in the quantification of relevant allergens in allergenic extracts. Eur Ann Allergy Clin Immunol. 2013;45(Suppl 2):33-37.

20. Helsper JP, Gilissen LJ, van Ree R, America AH, Cordewener JH, Bosch D. Quadrupole time-of-flight mass spectrometry: a method to study the actual expression of allergen isoforms identified by PCR cloning. J Allergy Clin Immunol. 2002;110(1):131-138.

21. Park JW, Kim KS, Jin HS, et al. Der $\mathrm{p} 2$ isoallergens have different allergenicity, and quantification with 2-site ELISA using monoclonal antibodies is influenced by the isoallergens. Clin Exp Allergy. 2002;32(7): 1042-1047.

22. Puccinelli P, Natoli V, Dell'Albani I, et al. Evaluation of stability of allergen extracts for sublingual immunotherapy during transport under unfavourable temperature conditions with an innovative thermal insulating packaging. Eur Ann Allergy Clin Immunol. 2013;45(Suppl 2): 39-48.

23. Incorvaia $\mathrm{C}$, Frati F. One century of allergen-specific immunotherapy for respiratory allergy. Immunotherapy. 2011;3(5):629-635.

24. Frati F, Incorvaia C, Passalacqua G. Efficacy of sublingual immunotherapy. JAMA. 2013;310(6):643-644.
25. Di Bona D, Plaia A, Leto-Barone MS, La Piana S, Di Lorenzo G. Efficacy of subcutaneous and sublingual immunotherapy with grass allergens for seasonal allergic rhinitis: a meta-analysis-based comparison. J Allergy Clin Immunol. 2012;130(5):1097-1107.

26. Bousquet J, Lockey R, Malling HJ. Allergen immunotherapy: therapeutic vaccines for allergic diseases. A WHO position paper. $J$ Allergy Clin Immunol. 1998;102(4 Pt 1):558-562.

27. Frati F, Incorvaia C, Scurati S, Sensi L, Marcucci F. Dose-dependence of sublingual immunotherapy shown by meta-analysis. J Allergy Clin Immunol. 2011;127(4):1076-1077.

28. Frati F, Scurati S, Puccinelli P, et al. Development of a sublingual allergy vaccine for grass pollinosis. Drug Des Devel Ther. 2010;4:99-105.

29. Batard T, Nony E, Dayang C, et al. Interest of mass spectrometry-based quantification of relevant allergen to improve the standardization of allergen extracts. J Allergy Clin Immunol. 2014;133(Suppl):221.

30. Ott H, Sieber J, Brehler R, et al. Efficacy of grass pollen sublingual immunotherapy for three consecutive seasons and after cessation of treatment: the ECRIT study. Allergy. 2009;64(9):1394-1401.

31. Incorvaia $C$, Frati F. On mechanism of action of sublingual immunotherapy. Pediatr Allergy Immunol. 2009;20(1):102.

32. Akdis CA, Akdis M. Mechanisms of action of allergen-specific immunotherapy. J Allergy Clin Immunol. 2011;127(1):18-27.

33. Moingeon P. Update on immune mechanisms associated with sublingual immunotherapy: practical implications for the clinician. J Allergy Clin Immunol Pract. 2013;1(3):228-241.

34. Masieri S, Trabattoni D, Incorvaia $C$, et al. A role for Waldeyer's ring in immunological response to allergens. Curr Med Res Opin. 2014;30(2): 203-205.

35. Noirey N, Rougier N, André C, Schmitt D, Vincent C. Langerhanslike dendritic cells generated from cord blood progenitors internalize pollen allergens by macropinocytosis, and part of the molecules are processed and can activate autologous naive T lymphocytes. J Allergy Clin Immunol. 2000;105(6 Pt 1):1194-1201.

36. Seppälä U, Dauly C, Robinson S, Hornshaw M, Larsen JN, Ipsen H. Absolute quantification of allergens from complex mixtures: a new sensitive tool for standardization of allergen extracts for specific immunotherapy. J Proteome Res. 2011;10(4):2113-2122.

37. Calderon MA, Demoly P, Gerth van Wijk R, et al. EAACI: A European Declaration on Immunotherapy. Designing the future of allergen specific immunotherapy. Clin Transl Allergy. 2012;2(1):20.

38. Frati $\mathrm{F}$. The allergen immunotherapy must fly to quality and beyond. Eur Ann Allergy Clin Immunol. 2013;45(Suppl 2):3.

39. Canonica GW, Ansotegui IJ, Pawankar R, et al. A WAO - ARIA $\mathrm{GA}^{2} \mathrm{LEN}$ consensus document on molecular-based allergy diagnostics. World Allergy Organ J. 2013;6(1):17.

40. Scala E. Molecule-based diagnosis and allergen immunotherapy. Eur Ann Allergy Clin Immunol. 2013;45(Suppl 2):25-32.
Biologics: Targets \& Therapy

\section{Publish your work in this journal}

Biologics: Targets \& Therapy is an international, peer-reviewed journal focusing on the patho-physiological rationale for and clinical application of Biologic agents in the management of autoimmune diseases, cancers or other pathologies where a molecular target can be identified. This journal is indexed on PubMed Central, CAS, EMBase, Scopus
Dovepress

and the Elsevier Bibliographic databases. The manuscript management system is completely online and includes a very quick and fair peerreview system, which is all easy to use. Visit http://www.dovepress. com/testimonials.php to read real quotes from published authors. 